\title{
A personal reflection on researching and writing my dissertation: The effect of homelessness on information access, identity formation and social interaction
}

\author{
Thomas Muggleton
}

\begin{abstract}
This is a brief account of research undertaken for a dissertation, The effect of homelessness on information access, identity formation and social interaction, submitted to the University of Strathclyde in 2010 for the degree of M.Sc. Information and Library Studies. The dissertation aimed to add to the information science literature on homelessness, which often focuses on practical information needs, by considering access to information sources - specifically newspapers, television, radio, books and the internet - that may affect 'higher-level' needs. The findings contradicted initial expectations regarding the extent to which homelessness would restrict access to these information sources, but the decision to address higher-level information needs proved well-founded, since participants clearly pursued these alongside more basic physiological needs. The research has implications for the provision of information and services within both organisations serving the homeless and public libraries. This paper presents the research and its findings from a personal perspective.
\end{abstract}

\section{Introduction}

Along with the rest of my ILS class at the University of Strathclyde, I researched and wrote my dissertation in the summer of 2010. We had to choose a topic for this project months earlier, but now that I had actually begun to lay the groundwork for it, I was beginning to have some doubts.

I had chosen to focus on a marginalised group because, given the time and effort required to produce the dissertation, I wanted to feel that there was at least the possibility for it to serve some wider purpose than attaining my M.Sc. Similarly, I had been drawn to ILS at least in part because of the potential impact that information services, and particularly public libraries, can have for economically disenfranchised people, and so I wanted to explore and develop my understanding of one aspect of this. Overall, I was more optimistic about developing my own

\section{Author}

Thomas Muggleton is currently working as a school librarian in Glasgow.

Email: tmuggleton@hotmail.co.uk 
understanding than of the potential for any impact on anyone else, but it seemed like a noble ambition anyway.

Having done some background reading, I thought that the way I was approaching the subject matter could address a gap in the information and library science literature. The LIS research I had read tended to focus on practical information procurement and use, particularly in relation to technology (Hersberger, 2003; Le Dantec and Edwards, 2008; Roberson and Nardi, 2010); practical concerns, such as how to present information in homeless service agencies (Woelfer et al., 2008; Woelfer and Hendry, 2009); and advocacy for the right to use public library services (Harris and Simon, 2009; Heffernan, 2009; Hersberger, 2005). Although I could understand this focus on practical needs when considering such a physically vulnerable group of people, I also felt there was a danger that higherlevel information needs could be neglected. Furthermore, I felt that focusing on an individual's needs simply as a 'homeless person' may have a detrimental effect, perhaps even serving to compound marginality and differentiation from wider society.

Given this apparent gap, and the reasoning behind addressing it, I felt hopeful about my plans. However, I also felt some trepidation regarding the feasibility and usefulness of the study, and with regards to my own inexperience of interacting with homeless people. The preliminary discussions I held with experienced social workers to advise me on various aspects of the interviews both reassured me and revealed the extent of my ignorance in some areas. All of these people, including those at Glasgow City Mission through whom I would conduct the interviews, showed an interest in the subject matter of my dissertation, which was promising. However, in these discussions I also discovered - among many other things - that the homeless population of Glasgow does not generally sleep on the streets. This challenged one of the unconscious assumptions I had carried into the project and made me wonder whether more fundamental, unseen assumptions might be waiting to reveal themselves; at this early stage I could only hope that that was not the case and wait and see what would come up.

\section{Literature review}

Meanwhile, I tried to read quite widely in an attempt to gain some understanding of theories of identity-formation and social interaction among homeless populations. I found literature in the fields of sociology and psychology to be particularly instructive in this regard.

Sociological studies (Järvenin, 2003; Snow and Anderson, 1987) gave an insight into the effects that homelessness may have on identity-formation, such as "distancing" from imputed, negative social identities; "embracement" of social responsibilities to one's peers; and "fictive storytelling" to bridge the gap between desired self-perception and reality. Snow and Anderson introduced the idea of a "humanistic coefficient" - that the imputation of meaning to one's surroundings is common to all people regardless of social status (Snow and Anderson, 1987, 1365) - which supported my concern with examining higher-level needs. 
Another sociological study (Conley, 1996), a policy paper (Anderson, 1996) and two psychology papers (Sumerlin, 1996; Sumerlin and Bundrick, 1997) informed my research regarding the social norms, social responsibilities and mutual dependencies that often exist among homeless people. Social norms were seen to restrict and influence behaviour, potentially perpetuating homelessness.

However, in such a precarious position, informal networks and social ties were also considered vital for daily survival. These papers also highlighted difficulties associated with homelessness, such as existential crises and problems of low selfesteem, which alternative conceptions of self and identity could help to negotiate.

A further sociological study (LaGory et al., 2001), two articles from medical journals (Ensign and Bell, 2004; Barry et al., 2002) and a policy paper for homeless services (Slesnick et al., 2008) gave useful context and different perspectives on identity-formation and difficulties facing homeless people. My literature review also drew on publications from homeless charities to elucidate some of these organisations' strategies (National Coalition for the Homeless, 2009a; Shelter, 2009) and develop a fuller understanding of some of the difficulties facing homeless people (National Coalition for the Homeless, 2009b). Finally, a human geography paper (Hodgetts et al., 2008), which discussed social exclusion, media portrayals of homeless people, and occupation of public spaces by homeless people to facilitate feelings of social inclusion, completed the appraisal of literature about homelessness from other academic disciplines.

This literature helped to allay some of my fears regarding the legitimacy of my study, since it seemed to build up a picture congenial to my aims. This was further reinforced by statistics that, for the most part, seemed to confirm my assumptions regarding an 'informational mainstream' (Alexa, 2010; BARB, 2010a; BARB, 2010b; BARB, 2010c; BML, 2010; Luft, 2010; Office for National Statistics, 2010a; Office for National Statistics, 2010b; Press Gazette, 2010a; Press Gazette, 2010b; RAJAR, 2010; Willings Press Guide, 2007).

What I meant by an 'informational mainstream' was essentially that the predominance of a few major players in the prevailing forms of mass media, such as newspapers, radio, television, books, and the internet, creates a fairly centralised transmission of information and, subsequently, has a significant effect on consolidating and homogenising discourse. One of the examples cited in my dissertation was that, of the 26.8 million households in the UK in 2010, 26 million owned a television (BARB, 2010a), while the 4 major channels in the UK BBC1, BBC2, ITV1 and Channel 4 - averaged over $50 \%$ of television viewing share between them for the period of January 2010 to May 2010 (BARB, 2010b).

Moreover, I had read a paper on social exclusion which discussed "multidimensional cumulative disadvantage" and lack of access to formal means of social capital (Daly and Silver, 2008, 548-549). This seemed to cohere with the story of limited access to formal information sources, and the resulting importance of informal information networks, that I was expecting to tell.

However, an extended book review by anthropologist Mary Madden (Madden, 2003) introduced some new concerns. In the review, Madden is heavily critical of the approach taken by two anthropologists to the study of homeless populations. The two main criticisms that stuck in my mind concerned, firstly, "exoticizing" 
the poor as a distinct 'other', and, secondly, creating a narrative that reflected the preoccupations of the researcher rather than the reality for the people who were the subjects of the research. The first point made me determined to take the people I was interviewing at face value and not carry any preconceptions into the interviews - although I was to find out later that there was more to this than I realised. The second point made me question my own motivations, but, since it seemed unrealistic to try to pin these down with any certainty, I satisfied myself with trying as hard as I could not to colour any of the interviewees' responses with my own ideas.

\section{Method}

To allow for some degree of participant-led responses but also compensate for my lack of research experience, I decided on semi-structured interviews. After I had revised my demographic questionnaire and skeletal interview script several times, and conducted a couple of practice runs with friends, I was ready to undertake my interviews. I had been in touch with a number of service agencies, but the most positive response had been from staff at Glasgow City Mission, who offered to introduce me to prospective participants and to provide a private space to conduct the interviews. I decided not to offer an incentive due to ethical concerns over coercion, and simply relied upon individuals' generosity. I conducted 18 interviews over six sessions - three in the afternoon and three in the evening between the $7^{\text {th }}$ and the $18^{\text {th }}$ of July, 2010 .

The nerves which accompanied my visits to the Mission, particularly the first couple, seemed to give some indication of the difficulty of abandoning sociallyimbued prejudices. However, it was also a novel situation for me, both in terms of surroundings and carrying out interviews, so I managed not to berate myself too much for this.

The interviews generally went more smoothly as I went along, but there was a steep learning curve. I probably also relaxed a little more with every interview as I gained more experience and got closer to completing the research. However, I also quickly realised that the earlier insight about rough sleeping was not the only thing I had missed. In spite of my concerns to avoid "exoticizing" anyone and to maintain a blank slate until something was written on it, by the end of the second session on the first day of interviews I realised that I had conceived a fundamental distinction between the experiences of 'the homeless' and 'the housed' in some aspects of my study.

\section{Findings}

Luckily I had been paying attention in Research Methods 101, so my question did not bind me to any foregone conclusions. However, the realisation of this assumption, and the fallacy of it, felt like a revelation of sorts - if only because I felt as if I had not seen the wood for the trees. It seemed so obvious, and yet some stubborn, elusive assumption had meant that there were some ideas in my initial conception of the research that simply did not relate to reality. As I spoke to more interviewees, I realised that most had interests, concerns and behaviours that would not distinguish them from the general population in any way. Many were 
facing difficulties, or had faced difficulties, beyond just not having enough money, but they were generally not defined by such problems - it was just one aspect of their life. Others were simply at the wrong end of the wage scale, had been unlucky, and were only homeless for a very short time.

I probably would have told anyone all this before I conducted the research, but actually meeting people made it much more real. It is easy to say that someone is just like anyone else, but once you have actually spoken to that person about their life, what interests them, what their aspirations are, and so on, it goes beyond being a theoretical belief to become an experiential truth. That may sound like an excessively metaphysical description of a few conversations, but for me it made a palpable difference to how I conceived of the research questions I had set myself.

For many of the participants then, particularly those who were more resourceful, homelessness was more of an inconvenience than a fundamental obstacle to participating in the information mainstream. Their opinions of mass media and advertising were consequently indistinguishable from what I would expect to hear in most conversations about such things. Similarly, there were no earth-shaking revelations regarding identity-formation and social interaction; the findings again cohered with my own intangible and indefinable sense of normality.

However, there were a number of more nuanced findings that were of interest. Although many participants seemed fairly nonchalant that, if they wanted to, they could secure access to all the forms of media and communication I mentioned television, newspapers, books, internet, and the radio - some participants did mention difficulties with either functional literacy or computer literacy. This was largely unsurprising, though, since the backgrounds and circumstances of many participants would provide scarce opportunity to develop these skills. It was also consistent with various reports I had found that reported illiteracy as a potential cause and perpetuating factor in homelessness (Homeless Link, n.d; Simmons, n.d.; Warnes et al., 2003, 35).

Nonetheless, there were some significant differences between interviewees regarding the causes of these difficulties. Some did attribute them to circumstances, but others suggested either that increased awareness on their part allowed them to rise above their circumstances, or that their own "chaotic lifestyle" was more of an obstacle in developing new skills. This difference of interpretation also appeared to mark a more profound difference in background, outlook and/or abilities, which was an important theme throughout the research: the eighteen participants were often very different from each other, and this seemed to warn against excessive generalisation.

Indeed, the variety among the interviewees again highlighted the importance of avoiding binary distinctions between the homeless and the housed. Homelessness had certainly not had a uniform, all-consuming effect on the participants in my study, and for some it was a relatively minor event in their life. Having said that, I obviously do not wish to understate the often traumatic experiences that lead to homelessness, or the negative effects that the experience of homelessness can have on a person. 
In fact, such experiences sometimes seemed evident in the responses given to questions about the use of various information sources. One participant, who had become homeless after struggling with a gambling addiction, seemed wary of the addictive nature of the internet and subsequently limited his use of it. Similarly, a participant who had suffered a nervous breakdown reported that he now deliberately did not own a television because he had found himself watching it simply because it was there; he told me that he considered himself addicted to television at one point, watching things that he had no interest in, and consequently not finding time for the things he wanted to do. Conversely, the same participant described how he had found new value in social science literature, particularly books about psychology, which he said had aided his recovery and had only begun to make sense to him in light of his past experiences. Finally, a participant who had reported instances of abuse as a child told me that he avoided reading newspapers, watching certain television programmes or listening to mainstream music because he was concerned about the effect that it would have on his mental well-being; instead, he tended to watch family films or stick to easy listening music which he found much more conducive to relaxation.

While a direct causal link between past experiences and present behaviour was not really drawn by the participants themselves, these responses did suggest that many participants were well aware of the effect that information and information sources would have upon them. In the same way, there was widespread scepticism among participants when they were asked about news sources, with significant awareness of the distortions of news reporting, particularly in newspapers. This may be more reflective of the times that we live in than the circumstances of these individuals, but it would seem short-sighted to completely discount the effect of homelessness upon these responses; a life-changing negative experience will always bring new perspectives, and often new lucidity, to subsequent situations and questions, and a homeless episode is unlikely to be an exception.

The discussions I had in this regard reminded me of a section in one of John Sumerlin's papers which described the heightened self-awareness among the homeless participants in his study (Sumerlin, 1996, 887). For many of the participants in my study, important positives had been taken from their negative experiences. Some expressed these more explicitly than others, saying that it had helped them grow up or that they had learned more about the reality of homelessness, while others seemed to feel more confident of being able to deal with difficult situations. Moreover, many had established new friendships or learned more about themselves through the experience. Indeed, especially given their circumstances, it was impossible not to be humbled by the positive outlook and insights given by a number of the participants.

\section{Conclusion}

While it is certainly a mistake to trivialise the difficulties of homelessness, it is also vital not to envisage an absolute dichotomy between the homeless and the housed. This study set out to emphasise the "humanistic coefficient" when considering homelessness in relation to Information and Library Studies, going beyond practical information to focus on the role of information in identity- 
formation and social interaction. The findings of this study did not upset expectations in this regard: participation in the information mainstream was widely considered important by the interviewees and their concerns were not limited to narrow pragmatism and day-to-day survival. However, access to information sources was generally easier for participants than anticipated, reinforcing the assumption of a "humanistic coefficient" but upsetting a contrary expectation regarding prohibitively curtailed access. Indeed, in many ways the experience of conducting the research revealed more commonalities between the homeless and the housed than was initially expected, and broke down some unconscious assumptions held by the researcher.

However, some participants did have difficulties with functional literacy and computer literacy; these difficulties were sometimes explicitly linked to homelessness or circumstances leading to it, although at other times this link was unstated or expressly questioned by interviewees. Past experiences were also seen to affect how some participants obtained and used information, encouraging the use of certain kinds or sources of information and discouraging the use of others, depending on the individual. Furthermore, perhaps due to its history, the provision of services for the homeless in Glasgow is generally considered to be good in comparison to other areas of the United Kingdom, so a study in a different place might yield different results regarding ease of access to information.

Finally, in most cases in this study, the main changes resulting from homelessness in information needs and use were contextual rather than fundamental. This finding reinforces the view that public library services should continue to serve everybody, including the homeless, if they are to be truly universal in their scope. To state this may seem trite, but it is deemed necessary by the prejudicial attitudes towards marginalised communities, and particularly 'the homeless', in certain quarters of the library world (e.g. Cronin, 2002). Not only are such attitudes detrimental to public library goals of universal access to information, but, as the results of this study hopefully show, the heterogeneous nature of people who are homeless means that it is impractical and nonsensical to group them together except in the loosest possible sense. 


\section{References}

Alexa (2010) Top sites in United Kingdom. URL: http://www.alexa.com/topsites/countries/GB [accessed 30.06.10].

Anderson, R. (1996) Homeless violence and the informal rules of street life, Journal of Social Distress and the Homeless, 5(4), 369-380.

BARB (Broadcasters' Audience Research Board) (2010a) Television ownership in private domestic households 1956-2010 (millions). URL:

http://www.barb.co.uk/facts/tvOwnershipPrivate [accessed 16.06.10].

BARB (Broadcasters' Audience Research Board) (2010b) Monthly multi-channel viewing summary. URL: http://www.barb.co.uk/report/monthlyViewing?_s=4 [accessed 29.06.10].

BARB (Broadcasters' Audience Research Board) (2010c) Average weekly viewing. URL: http://www.barb.co.uk/graph/weeklyViewing?_s=4 [accessed 30.06.10].

Barry, P. J., Ensign, J., and Lippek, S. H. (2002) Embracing street culture: fitting health care into the lives of street youth, Journal of Transcultural Nursing, 13(2), $145-152$.

BML (2010) Sizing the UK book market. URL:

http://www.bookmarketing.co.uk/index.cfm/asset_id,885/index.html [accessed 16.06.10].

Conley, D. C. (1996) Getting it together: social and institutional obstacles to getting off the streets, Sociological Forum, 11(1), 25-40.

Cronin, B. (2002) What a library is not, Library Journal, 127(19), 46.

Daly, M., and Silver, H. (2008) Social exclusion and social capital: a comparison and critique, Theory and Society, 37(6), 537-566.

Ensign, J., and Bell, M. (2004) Illness experiences of homeless youth, Qualitative Health Research, 14(9), 1239-1254.

Harris, N., and Simon, A. (2009) Still barriers to overcome, Public Library Journal, 24(4), 25-27.

Heffernan, F. (2009) Outside story: welcoming the homeless, Public Library Journal, 24(3), 6-7.

Hersberger, J. (2003) Are the economically poor information poor? Does the digital divide affect the homeless and access to information? In: Peekhaus, W. C., and Spiteri, L. F. (eds.) Bridging the digital divide: equalizing access to information and communication technologies $\left(31^{\text {st }}\right.$ CAIS/ACSI Conference : 30.05.03-01.06.03 : Halifax, Nova Scotia). Toronto : CAIS/ACSI. 236-249.

Hersberger, J. (2005) The homeless and information needs and services, Reference and User Services Quarterly, 44(3), 199-202.

Hodgetts, D., et al. (2008) A trip to the library: homelessness and social inclusion, Social and Cultural Geography, 9(8), 933-953. 
Homeless Link (n.d.) Assessing support needs - new and existing tenants. URL: http://homeless.org.uk/Assessing-support-needs-case-study [accessed 11.08.10].

Järvinen, M. (2003) Negotiating strangerhood: interviews with homeless immigrants in Copenhagen, Acta Sociologica, 46(3), 215-230.

LaGory, M. Fitzpatrick, K. and Ritchey, F. (2001) Life chances and choices: assessing quality of life among the homeless, Sociological Quarterly, 42(4), 633651.

Le Dantec, C. A., and Edwards, W. K. (2008) Designs on dignity: perceptions of technology among the homeless. In: Czerwinski, M., Lund, A., and Tan, D. (eds.) Proceedings of the ACM CHI 2008 Conference on human factors in computing systems $\left(25^{\text {th }}: 05.04 .08-10.04 .08\right.$ : Florence). New York: ACM Press. 627-636.

Luft, O. (2010) ABCs: Times drops 13\% as all qualities fall, Press Gazette: Journalism Today. URL:

http://www.pressgazette.co.uk/story.asp? sectioncode $=1 \&$ storycode $=44910 \& \mathrm{c}=1$ [accessed 01.07.10].

Madden, M. (2003) Braving homelessness on the ethnographic street with Irene Glasser and Rae Bridgman, Critique of Anthropology, 23(3), 289-304.

Muggleton, T. (2010) The effect of homelessness on information access, identity formation and social interaction, M.Sc. dissertation, University of Strathclyde, Glasgow.

Muggleton, T. H., and Ruthven, I. (2012) Homelessness and access to the informational mainstream, Journal of Documentation, 68(2), 218-237.

National Coalition for the Homeless (2009a) Why are people homeless? URL: http://www.nationalhomeless.org/factsheets/why.html [accessed 02.07.10].

National Coalition for the Homeless (2009b) Hate crimes and violence against people experiencing homelessness. URL:

http://www.nationalhomeless.org/factsheets/hatecrimes.html [accessed 06.07.10].

Office for National Statistics (ONS) (2010a) Use of the internet. URL:

http://www.statistics.gov.uk/cci/nugget.asp?id=1711 [accessed 29.06.10].

Office for National Statistics (ONS) (2010b) Use of ICT at home. URL:

http://www.statistics.gov.uk/cci/nugget.asp?id=1710 [accessed 29.06.10].

Press Gazette (2010a) ABCs: despite election all quality dailies fall y-o-y, Press Gazette: Journalism Today. URL:

http://www.pressgazette.co.uk/story.asp? sectioncode $=1 \&$ storycode $=45576 \& \mathrm{c}=1$ [accessed 01.07.10].

Press Gazette (2010b) ABCs: Circulations of just two nationals increase y-o-y, Press Gazette: Journalism Today. URL:

http://www.pressgazette.co.uk/story.asp? sectioncode $=1 \&$ storycode $=45444 \& \mathrm{c}=1$ [accessed 01.07.10].

RAJAR (Radio Joint Audience Research Ltd) (2010) Listening figures - quarterly listening. URL: http://www.rajar.co.uk/listening/quarterly_listening.php [accessed 29.06.10]. 
Roberson, J., and Nardi, B. (2010) Survival needs and social inclusion: technology use among the homeless. In: Inkpen Quinn, K., Gutwin, C., and Tang, J. C. (eds.) Proceedings of the 2010 ACM Conference on computer supported cooperative work (CSCW 2010) $\left(13^{\text {th }}: 06.02 .10-10.02 .10\right.$ : Savannah, Georgia). New York: ACM Press. 445-448.

Shelter (2009) Annual report and accounts 2008/09. URL: http://scotland.shelter.org.uk/_data/assets/pdf_file/0016/212074/Annual_Report 08-09.pdf [accessed 02.07.10].

Simmons, W. (n.d.) Tackling exclusion: literacy and homelessness in NI. URL: http://lawcentreni.org/publications/frontline-magazine/374.html [accessed 11.08.10].

Slesnick, N., et al. (2008) How to open and sustain a drop-in center for homeless youth, Children and Youth Services Review, 30(7), 727-734.

Snow, D., and Anderson, L. (1987) Identity work among the homeless: the verbal construction and avowal of personal identities, The American Journal of Sociology, 92(6), 1336-1371.

Sumerlin, J. R. (1996) What have you learned from your homeless experience? A phenomenological approach for counseling unsheltered homeless men, Psychological Reports, 79, 883-890.

Sumerlin, J. R., and Bundrick, C. M. (1997) Research on homeless men and women: existential-humanistic and clinical thinking, Psychological Reports, 80, $1303-1314$.

Warnes, A., et al. (2003) Homelessness factfile. URL:

http://www.crisis.org.uk/data/files/publications/factfile_Full.pdf [accessed 11.08.10].

Willings Press Guide (2007) Volume 1: United Kingdom. Chesham, Bucks.: Romeike Ltd.

Woelfer, J. P., and Hendry, D. G. (2009) Stabilizing homeless young people with information and place, Journal of the American Society for Information Science and Technology, 60(11), 2300-2312.

Woelfer, J. P., et al. (2008) Value considerations in an information ecology: printed materials, service providers and homeless young people, Proceedings of the American Society for Information Science and Technology, 45(1), 1-9.

\section{The Occasion}

This paper was written to accompany the award of the 2011 LIRG Student Award for best dissertation. The dissertation, entitled The effect of homelessness on information access, identity formation and social interaction, can be found in Muggleton (2010). A shortened account of the study can be found in Muggleton and Ruthven (2012). 


\section{Acknowledgement}

I would again like to thank the staff and clients of the Glasgow City Mission, who very generously shared their time and experiences, and the individuals who assisted in the preparation for the interviews. I would also like to thank my dissertation supervisor, who was very supportive throughout the project.

\section{Open access and copyright}

Library and Information Research is an open access journal. A freely available copy of this paper may be downloaded from the journal's website: http://www.lirgjournal.org.uk/lir/ojs/index.php/lir.

Copyright and associated moral rights in works published in Library and Information Research are retained by the author(s) but this paper may be used freely, with proper attribution, in educational and other non-commercial settings. 